need of medical care and respiratory support were included. After uncomplicated postnatal transition of $15 \mathrm{~min}$, the cerebral oxygenation (TOI) was measured on the right forehead using NIRO 200NX. The diameter of PFO was measured using echocardiography. The influence of PFO on TOI was investigated by applying correlation-analysis.

Results 25 term neonates after uncomplicated adaptation period of 15 min (APGAR: 9/10/10) were included. The mean gestational age was $38.7 \pm 0.9$ weeks and the mean birth weight $3114.0 \pm 423.9 \mathrm{~g}$.

The mean cerebral oxygen saturation was $76.6 \pm 8.9 \%$ and the mean diameter of PFO was $2.3 \pm 0.7 \mathrm{~mm}$.

The correlation-analysis could show a trend of negative correlation between the cerebral oxygen saturation and the diameter of PFO, but this correlation was not statistically significant.

Conclusion In term neonates after uncomplicated transition, the diameter of PFO has no influence on the cerebral oxygen saturation.

\section{0-027 MICROCIRCULATION WITHIN THE FIRST MINUTES AND FIRST 24 HOURS OF LIFE IN HEALTHY TERM NEWBORNS}

F Kulali, E Ergenekon, E Kazanci, S Unal, S Aktas, I Hirfanoglu, E Onal, C Turkyilmaz, E Koc, Y Atalay. Newborn Medicine, Gazi University Hospital, Ankara, Turkey

\subsection{6/archdischild-2014-307384.96}

Background and aims Microcirculation is important to ensure adequate tissue oxygenation and nutrient delivery. Clinical findings, perfusion index (PI) measurements are used to assess microcirculation. Side stream dark field (SDF) imaging is a noninvasive method of assessing microcirculation by means of a videomicroscope.

This study aimed to assess microcirculation in healthy term newborns born either by spontaneous vaginal delivery (SVD) or caesarean section $(\mathrm{C} / \mathrm{S})$.

Methods The assessments were done within the first $30 \mathrm{~min}$ of life (T0) and repeated at the 24th hour of life (T1). Microcirculation was assessed from axillary skin by using SDF technique with Microscan device where total and perfused vessel density (TVD, PVD) and microvascular flow index (MFI) were calculated, as well as by using microcirculation score (MS) based on capillary refill time, skin colour and warmth and PI measured by Masimo Radical7 pulse oxymeter. Vital signs were also recorded. Nonparametric tests were used for statistical analysis.

Results Twelve newborns born by SVD and 25 newborns born $\mathrm{C} / \mathrm{S}$ were included. The mean, $\mathrm{SD}$, median values for temperature, TVD, PVD, MFI, MS, and PI at T0 and T1 are as follows;

T0: Temp:36 \pm 0,44(36,1), TVD: $18,79 \pm 1,49(18,81)$, PVD: $18,73 \pm 1,5(18,81)$, MFI: $3,07 \pm 0,25(3)$, MS: $2,14 \pm$ 1,36(2), PI: $1,84 \pm 0,97(1,75)$.

T1: Temp:37,1 \pm 0,26(37,1), TVD: 18,93 \pm 2,1(18,73), PVD: $18,9 \pm 2,13(18,73)$, MFI: 3,17 \pm 0,32(3,1), MS:1,65 \pm $0,48(2)$, PI: $1,9 \pm 0,8(2)$.

Temperature was significantly and MFI was slightly higher at T1 compared to T0 ( $\mathrm{p}=0,001$ and $\mathrm{p}=0,04)$.

No difference was observed between SVD or C/S groups or at different times within the same group.

Conclusions Peripheral microcirculation in general is not affected by mode of delivery in term healthy newborns and doesn't seem to change significantly within the first $24 \mathrm{~h}$ of life.

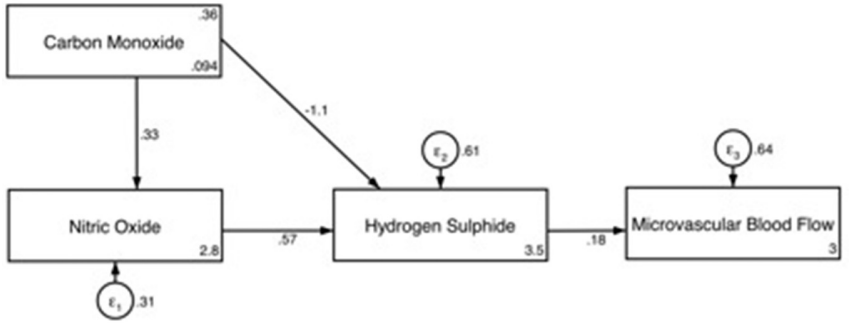

Abstract 0-028 Figure 1

\section{0-028 MICROVASCULAR TONE IN THE PRETERM NEONATE: GASOTRANSMITTER INTERACTIONS MAY BE THE KEY}

${ }^{1} \mathrm{R}$ Dyson, ${ }^{2} \mathrm{H}$ Palliser, ${ }^{3}$ L Latter, ${ }^{4} \mathrm{G}$ Chwatko, ${ }^{4} \mathrm{R}$ Glowacki, ${ }^{5}$ I Wright. ${ }^{1}$ Illawarra Health and Medical Research Institute, University of Wollongong, Wollongong, Australia; ${ }^{2}$ Mother and Babies Research Centre HMRI, University of Newcastle, Newcastle, Australia; ${ }^{3}$ Hunter Medical Research Institute, University of Newcastle, Newcastle, Australia, ${ }^{4}$ Environmental Chemistry, University of Lodz, Lodz, Poland; ${ }^{5}$ School of Medicine, University of Wollongong, Wollongong, Australia

\subsection{6/archdischild-2014-307384.97}

Background and aims Hydrogen sulphide $\left(\mathrm{H}_{2} \mathrm{~S}\right)$ can be produced by one of two enzymes: CSE or CBS. $\mathrm{H}_{2} \mathrm{~S}$ is associated with transitional microvascular tone dysregulation in the preterm infant. We have animal model evidence that increases in $\mathrm{H}_{2} \mathrm{~S}$ associated with microvascular dysregulation are driven by CSE-dependent mechanisms. Nitric oxide (NO) and carbon monoxide (CO) also play a role in the transitional circulation of preterm neonates. The aim of this study was to characterise the interrelationships of all 3 gasotransmitters using structural equation modelling analysis.

Methods 90 preterm neonates were studied at $24 \mathrm{~h}$ postnatal age. Microvascular studies were performed by laser Doppler. Arterial $\mathrm{COHb}$ levels (a measure of $\mathrm{CO}$ ) were determined through co-oximetry. $\mathrm{NO}$ was measured as total nitrate and nitrite in urine. $\mathrm{H}_{2} \mathrm{~S}$ was measured as urinary thiosulphate by liquid chromatography.

Results We observed a positive relationship between $\mathrm{NO}$ and $\mathrm{H}_{2} \mathrm{~S}(\mathrm{p}=0.008, \mathrm{r}=0.28)$ and an inverse relationship between $\mathrm{CO}$ and $\mathrm{H}_{2} \mathrm{~S}(\mathrm{p}=0.01, r=-0.33)$. No relationship was observed between NO and CO ( $\mathrm{p}=0.18, \mathrm{r}=0.18)$. Structural equation modelling was used to examine the combination of these effects on microvascular blood flow. The model with the best fit $\left(\chi^{2}=1.11\right)$ is presented.

Conclusions NO production positively related to $\mathrm{H}_{2} \mathrm{~S}$ production. Previous studies report that $\mathrm{NO}$ inhibits $\mathrm{H}_{2} \mathrm{~S}$ production via the enzyme CBS but induces CSE expression. These results suggest that in the preterm newborn, CSE expression is significantly modulated by NO. The relationship between $\mathrm{NO}$ and $\mathrm{CSE} / \mathrm{H}_{2} \mathrm{~S}$ may thus be critical to the deleterious higher microvascular blood flow.

\section{0-029 NEONATAL CIRCULATION MEASURED USING NEAR-INFRARED SPECTROSCOPY (NIRS) DIFFERS BETWEEN PRETERM AND TERM BORN INTRAUTERINE GROWTH RESTRICTED (IUGR) INFANTS}

${ }^{1} \mathrm{DM}$ Schmitz, ${ }^{1} \mathrm{JC}$ Tanis, ${ }^{1} \mathrm{MR}$ Boelen, ${ }^{2} \mathrm{~L}$ Casarella, ${ }^{2} \mathrm{CM}$ Bilardo, ${ }^{1} \mathrm{AF}$ Bos. ${ }^{1}$ Neonatology, University Medical Centre Groningen, Groningen, Netherlands; ${ }^{2}$ Perinatal Diagnostics Obstetrics and Gynecology, University Medical Centre Groningen, Groningen, Netherlands

10.1136/archdischild-2014-307384.98 